\title{
Transportation Poverty Alleviation Policies and Practical Experience
}

\begin{abstract}
Hui Zhao
China Academy of Transportation Sciences, Beijing, China

965368231@qq.com

ABSTRACT

The significant results achieved in transportation poverty alleviation is a major practice of socialism with Chinese characteristics that is worthy of in-depth summary. Based on the policy "process-tool" framework, it comprehensively describes the transportation poverty alleviation policy system, and systematically sorts out the practical practices of transportation poverty alleviation policies. Summarized and refined the work experience of poverty alleviation in transportation from the perspective of concepts and methods, the author believed that the scientific methods of transportation poverty alleviation were to adhere to the party's overall leadership, to build transportation with people's satisfaction, to promote the advanced concept of transportation poverty alleviation through building, management, maintenance and coordination, to take precise measures according to local conditions, to innovate the mechanism to guarantee the input and to consolidate the strong joint efforts. To consolidate and expand the achievements of transportation poverty alleviation and serve to comprehensively promote the rural revitalization, the author considers that it requires to make good use of the experience of transportation poverty alleviation, to do a good job in the linkage of work mechanisms, coordinate the work tasks of overall planning, and effectively ensure the linkage of policy elements.
\end{abstract}

Keywords : transportation poverty alleviation; policy "process-tool" framework; policy experience

\section{INTRODUCTION}

Transportation is a fundamental, leading and strategic industry in the national economy, as well as an important service industry. Transportation must go first to win the battle against poverty. General Secretary Xi Jinping profoundly elaborated on the importance of transportation in the fight against poverty and pointed out the construction of transportation infrastructure has a strong leading role. In some poor areas, building a ropeway or a section of highway can open a door for people to get rid of poverty and become rich[1]. This fully demonstrates that accelerating the implementation of transportation poverty alleviation is the first move to achieve targeted poverty alleviation, the key to breaking the bottleneck of economic and social development in poverty stricken areas, as well as an important measure to promote people's sharing of the results of transportation development. In accordance with the important instructions of General Secretary Xi Jinping and the decisions and arrangements of the CPC Central Committee, the transportation industry has made every effort to promote the work of transportation poverty alleviation, and fulfilled the solemn promise that no place will be left behind due to transportation on the road to well-off. With the joint efforts of party committees at all levels, governments and all relevant parties, breakthroughs and decisive achievements have been made in the fight against transportation poverty. Historical and dramatic changes have taken place in the transportation development poverty stricken areas. All towns where conditions permit and administrative villages have tarmac or cement roads and complete access to bus services. The transportation infrastructure network and service system of "external and internal connections, access to villages and buses to villages, safe and convenience" are basically formed. The fundamental and leading service role of transportation has been fully brought into play. 


\section{Policy Process and Policy Tools of China's Transportation POVERTY Alleviation}

\subsection{Policy "process-tool" framework for transportation poverty alleviation}

Based on the classic policy process model (Xue Lan) and the Rothwell policy tool model (Rothwell, etc.), Wang Yahua proposed a two-dimensional policy "process-tool" framework for targeted poverty alleviation. The policy process dimension is divided into four stages: "policy planning, policy implementation, policy evaluation, and policy termination". The dimension of policy tools is divided into three categories: supply side, environment side and demand side. Among them, the "supply-side" policy tool refers to the government's direct expansion of supply to help solve the relevant elements of poverty, so that the poor subjects can change the existing lifestyle, environment or state, such as the supply of transportation infrastructure, etc.; The "environmental-side"policy tool is the strategic deployment to effectively solve poverty alleviation problems indirectly through the optimization of the external poverty alleviation environment, such as the reform of the system and mechanism; And the "demandside" policy tool refers to the government's intervention to open up and stabilize the employment and industrial markets, such as the establishment of public welfare positions.

\begin{tabular}{|c|c|c|c|}
\hline Supply side & $\begin{array}{l}\text { Improve the planning } \\
\text { system } \\
\text { Set main development } \\
\text { indicators } \\
\text { Clarify sub-item } \\
\text { construction tasks }\end{array}$ & $\begin{array}{l}\text { Guarantee the capital investment } \\
\text { Promote the implementation of } \\
\text { tasks accurately } \\
\text { Implement special improvement } \\
\text { projects }\end{array}$ & $\begin{array}{l}\text { Streng then project fund } \\
\text { supervision } \\
\text { Rectify various kinds of } \\
\text { problems well }\end{array}$ \\
\hline $\begin{array}{l}\text { Environmental } \\
\text { side }\end{array}$ & $\begin{array}{l}\text { Clarify the acope of } \\
\text { transportation poverty } \\
\text { alleviation } \\
\text { Sign ministry-province } \\
\text { taclling agreements } \\
\text { Raise the construction } \\
\text { subsidy standard }\end{array}$ & $\begin{array}{l}\text { Deepen management and } \\
\text { maintenance reform } \\
\text { Play a typical demonstration and } \\
\text { leading role } \\
\text { Pay attention to publicity and } \\
\text { reports }\end{array}$ & $\begin{array}{l}\text { Establish and improve } \\
\text { reward and punishment } \\
\text { mechanisms } \\
\text { Carry ont special } \\
\text { campaign on comption } \\
\text { and work style issues }\end{array}$ \\
\hline Demand side & & Establish public welfare positions & \\
\hline
\end{tabular}

Figure 1 Transportation poverty alleviation policy system based on the policy "process-tool" framework

By sorting out the policy measures issued by the Ministry of Transport, this study sorted out and refined the China's transportation poverty alleviation macro policy tools. And the types were divided based on the two-dimensional policy "process-tool" framework, showing the panorama of transportation poverty alleviation policy system (see Figure 1).

\subsection{Transportation poverty alleviation practice based on policy tools}

According to the collected transportation poverty alleviation policy texts since the "13th Five-Year Plan", and based on the classification of the policy "processtool" framework, China's transportation poverty alleviation has the following practices.

\subsubsection{Policy Practice of "Policy Planning- Supply Side",}

The scope of transportation poverty alleviation was clarified. In accordance with the deployment requirements of the "Decision of the Central Committee of the Communist Party of China and the State Council on Winning the Fight against Poverty" and the "Guiding Opinions of the Central Committee of the Communist Party of China and the State Council on the Three-Year Action to Win the Fight against Poverty", the Ministry of Transport continued to improve the top-level design and policy system for transportation poverty alleviation, established and improved a "5-3-1" planning system consisting of a five-year plan, a three-year action plan, and an annual plan.

Main development indicators were set. In the 13th Five-Year Plan for transportation poverty alleviation plan, 7 quantitative indicators including the proportion of second-level and above roads connected to counties in poverty stricken areas were clearly put forward. By the end of 2020, the goal of achieving all of access to tarmac or cement roads and bus services (also called "Two Access") in conditional towns and administrative villages had been set as a bottom-line task.

Sub-item construction tasks were clarified. In the 13th Five-Year Plan for transportation poverty 
alleviation plan, connecting the main roads externally and internally, leading rural roads from villages to villages, improving safety capacity significantly, renovating transportation stations and improving water transportation infrastructure were listed as the key tasks, clarifying 13 conversation construction tasks in poverty stricken areas.

\subsubsection{Policy Practice of "Policy Planning- Supply Side"}

In addition to supporting 14 contiguous areas of dire poverty during the "Twelfth Five-Year Plan" period, the Ministry of Transport has included key counties in the national poverty alleviation development work, old revolutionary areas, minority autonomous counties, and border counties into the transportation poverty alleviation plan. The scope has increased from 680 counties (cities, districts) in the past to 1,177 counties (cities, districts), accounting for about $46 \%$ of the total number of counties (cities, districts) in the country.

Ministries and provinces work together. The Ministry of Transport signed the joint construction of transportation poverty alleviation agreement with 24 provinces, in which it was agreed that the ministries and provinces will jointly increase support and work together to achieve the goal and task of transportation poverty alleviation.

Subsidy standards were raised. During the "13th Five-Year Plan" period, the Ministry of Transport significantly increased the subsidy standards for transportation construction projects in poverty stricken areas. Among them, the national highway central investment subsidy standard has increased from an average of $15 \%$ to over $28 \%$ of the total project investment during the 12th Five-Year Plan period; the general state roads subsidy standard has increased from $30 \%$ to about $50 \%$; the subsidy standard for the access to tarmac or cement roads and bus services in conditional towns and administrative villages has been increased to more than $70 \%$ of the average project cost. After the state proposed to assault on the fortress of entrenched rural poverty like the "three regions and three prefectures" in 2017, the Ministry of Transport further increased the vehicle purchase tax subsidy standard for the "three prefectures (Liangshan in Sichuan, Nujiang in Yunnan, and Linxia in Gansu)".

\subsubsection{Policy Practice of "Policy Implementation- Supply Side"}

Funds were guaranteed to assist the fight. From 2012 to 2020, the Ministry of Transport invested nearly 1.47 trillion yuan of vehicle purchase tax funds into poverty stricken areas, accounting for about $61 \%$ of the country's total vehicle purchase tax, and driven to complete about
6.1 trillion yuan of fixed asset investment in roads and waterways in poverty stricken areas. During the "13th Five-Year Plan" period, new funds and projects were tilted to areas in deep poverty such as the "three regions and three prefectures". From 2016 to 2020, a total of about 270 billion yuan has been allocated for vehicle purchase tax funds. The ministry also promoted to include rural roads and other poverty alleviation projects into the priority list of local government bonds, implemented the use of refined petroleum products tax and fee reform funds for rural road management and maintenance, and ensured that fuel subsidies are used to support the development of rural bus services.

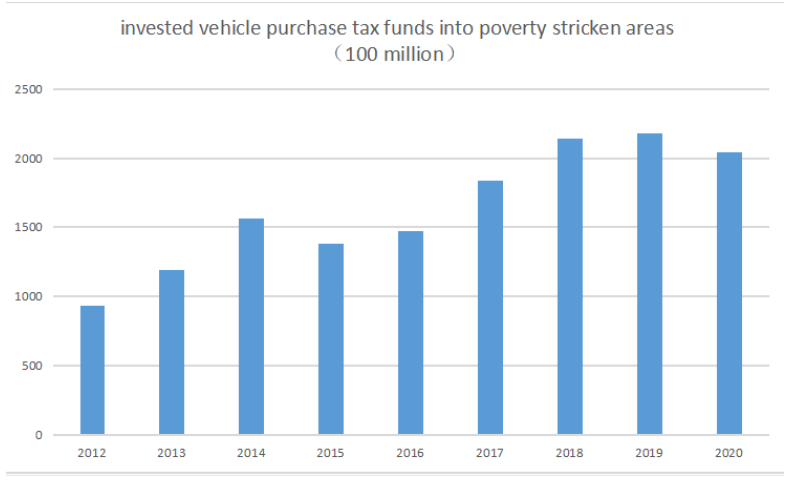

Figure 2 invested nearly vehicle purchase tax funds into poverty stricken areas

The implementation of tasks were accurately promoted. Taking the "Two Access" as an example, the Ministry of Transport had clarified the specific standards, together with 31 provinces (autonomous regions and municipalities) and the Xinjiang Production and Construction Corps, one by one examined and verified the basic data of about 32,000 towns and 540,000 administrative villages, so as to achieve the consistency of the list of towns and administrative villages with the data base, accurately locking the tasks and make them completed successfully. Flexibly adopt methods such as comprehensive local self-inspection, satellite remote sensing image verification, and ministerial-level on-site random inspections should be used to prevent "digital poverty alleviation" and data falsification by combining daily inspections with special inspections.

Specialized upgrading projects were implemented. The Ministry of Transport, together with China Post Group Corporation, guided poverty-stricken areas to continuously improve the efficiency of rural logistics resource utilization in making overall use of logistics resources such as transportation, postal services, express delivery, commerce, supply and marketing, and agriculture. The Ministry of Transport, in conjunction with the State Council's Poverty Alleviation Office, implemented the "Ropeway to Bridge" project, which was to help 7 provinces (regions) including Sichuan, Guizhou, Yunnan, Shanxi, Gansu, Qinghai, and Xinjiang transform all 309 pairs of ropeways into safe, convenient 
and reliable bridges, about 1168 administrative villages and 4000 villages involving a population of nearly 1.65 million people bid farewell to the "Ropeway Era".

\subsubsection{Policy Practice of "Policy Implementation- Environmental Side"}

To deepen the reform of rural road management and maintenance. The "Opinions of the General Office of the State Council on Deepening the Reform of the Rural Highway Management and Maintenance System" was introduced, establishing four systems of organization guarantee, financial guarantee, technical guarantee, and assessment guarantee for rural road management and maintenance. The Ministry of Transport issued the "Rural Highway Maintenance Management Measures", formulated and revised the "Rural Highway Maintenance Technical Specifications" and the "Rural Highway Maintenance Budget Preparation Measures", which made the technical standard system of the "Build, Manage, Protect and Operate rural roads (Four Good Rural Roads ) " improved. The Ministry of Transport vigorously promoted the system of roads chiefs, guided local governments to carry out their main responsibilities, and further improved the rural road management system.

To play a typical demonstration and leading role. The Ministry of Transport, together with the Ministry of Agriculture and Rural Affairs and the Poverty Alleviation Office of the State Council, put forward clear standards for the establishment of the "Four Good Rural Roads" national demonstration counties from eight aspects including the effective service of poverty alleviation and high satisfaction among the people. Demonstration counties across the country would have 10 million yuan in subsidies and every province was required to provide the same amount. The establishment work had given full play to the role of model driving and demonstration leading, encouraged to carry out the creation of provincial-level demonstration counties, towns and townships, and demonstration roads, formed a batch of advanced experiences that can be replicated, promoted and applicable, and effectively promoted the high-quality development of the "Four Good Rural Roads".

To pay attention to propaganda and reports. The Central Mainstream Media, such as "News Network", "People's Daily", Xinhua News Agency, reported the effectiveness of transportation poverty alleviation work, with the deeds of typical frontline figures moving and calling people, and actively conveyed the positive energy of transportation poverty alleviation. The leaders of the Ministry of Transport initiatively took participate in the press conference of the State Council Information Office, told stories of transportation poverty alleviation, and introduced the decisive victory of the transportation industry in poverty alleviation. The official website of the Ministry of Transport, "China Communications News", "China Water Transport News", "Civil Aviation News of China" set up poverty alleviation columns, leveraged the advantages of the new media platform, planned a series of live broadcasts, which actively created a good atmosphere of public opinion that was highly valued by the whole country and implemented by all parties.

\subsubsection{Policy Practice of "Policy Implementation - Demand Side"}

Creating public welfare positions for "Four Good Rural Roads" positively. The Ministry of Transport encouraged the general public, especially the poor, to voluntarily participate in the construction of poverty alleviation projects; encouraged local transportation departments to actively absorb the labor from poor families into public welfare positions, and mobilized the poor to participate in the construction, management, maintenance and transportation of rural roads , guided and strengthened skills training, and made every effort to help people with employment difficulties to find jobs. By September 2020, our country had created 288,000 public-service jobs in rural road-related areas, employed more than 703,000 jobs through work for building, management, maintenance and coordination, and absorbed 354,000 registered poor households.

\subsubsection{Policy Practice of "Policy Evaluation- Supply Side"}

Strengthening the supervision of funds for transportation poverty alleviation projects. The Ministry of Transport carried out special inspections on the quality and safety of transportation poverty alleviation projects and transportation poverty alleviation funds, and formulated the "Supervision and Management Measures for Transportation Poverty Alleviation Projects and Funds" so as to supervise the implementation of responsibilities, the execution of capital construction procedures, bidding and tendering, the progress of project construction, the standardized use of funds, and the payment of wages for migrant workers. The ministry strengthened market order management of highway and waterway construction in poor areas, improved the project construction quality, and maintained good market order. And also organized audits of transportation poverty alleviation funds in 25 provinces (autonomous regions, municipalities) and Xinjiang Production and Construction Corps that have transportation poverty alleviation tasks.

Special inspections and problem rectification for poverty alleviation should be done to solid. In response to the feedback from the central inspection team, the 
Ministry of Transport proposed that only by formulating rectification plans scientifically, making good overall plans, solving typical problems, avoiding the recurrence of similar problems, establishing corresponding rules and systems, taking measures comprehensively, filling in the loopholes and shortcomings of the system, can the task of shaking off poverty be accomplished with high quality.

\subsubsection{Policy Practice of "Policy Evaluation- Environmental Side”}

Establishing a reward and punishment mechanism for transportation poverty alleviation. The Ministry formulated reward and punishment measures to publicize and praise those provincial transportation departments that have made remarkable achievements in poverty alleviation and took incentive measures, and to supervise the rectification and implementation of those units that lag behind in their work and have outstanding problems.

Carrying out special campaigns to address corruption and misconduct in transportation poverty alleviation. The Ministry of Transport and the Discipline Inspection and Supervision Group dispatched by the Central Commission for Discipline Inspection of the Communist Party of China and the National Supervisory Commission worked together to carry out special campaigns, focusing on problems such as the lack of strong "four awareness" inadequate implementation of responsibilities, inaccurate work measures, non-standard fund management, unsound work style, and lax evaluation and supervision, which would promote the completion of poverty alleviation tasks with good style and strict discipline. The telephone number and mailbox for reporting corruption and misconduct issues in the poverty alleviation field was published on the official website of the Ministry. Once reports occur, they will be transferred to the relevant department for disposal in accordance with the management authority and the will be checked and dealt with accordingly in accordance with regulations and disciplines.

\section{Practical Experience of China's Transportation Poverty Alleviation POLICY}

The successful practice of transportation poverty alleviation is part of the success of targeted poverty alleviation under the new strategy of pooling nationwide resources. The new strategy takes the realization of national development and national security as the highest goal, takes scientific overall planning, concentration of forces, optimization mechanisms, and coordinated breakthroughs as its basic principles, takes modern major innovation projects as strategic measures, and takes innovative development of institutional arrangements as its core essence. Targeted poverty alleviation promoted by the new nationwide system has obvious strategic, synergistic, and innovative characteristics. Among them, the strategy is embodied in guiding the path of targeted poverty alleviation with advanced concepts; the synergy is reflected in the scientific approach to targeted poverty alleviation, and the concerted efforts to solve complex problems while making overall plans for the country; and innovation is aimed to improve the effectiveness of targeted poverty alleviation in using multiple tools. China's experience of poverty alleviation and development has been explored and formed through the guidance of advanced concepts and scientific methods under the new strategy of pooling nationwide resources.

\subsection{Conceptual dimension: To guide transportation poverty alleviation with advanced concepts}

Adhering to the party's overall leadership is the fundamental guarantee for transportation poverty alleviation to overcome difficulties. "The leadership of the CPC is the defining feature of Chinese socialism and the greatest strength of this system." It takes such a short time to build such a large-scale transportation facilities in impoverished areas. The fundamental reason lies in the strong leadership of the CPC Central Committee with Comrade Xi Jinping at its core in poverty alleviation, the scientific guidance for General Secretary Xi Jinping's important discourse on transportation poverty alleviation and the "Four Good Rural Roads" and the in-depth implementation of the decisions and policies made by the CPC Central Committee in poverty alleviation under the leadership of the Party Group of the Ministry of Transport and the strong support for transportation poverty alleviation of Party committees and governments at all levels.

The construction of transportation with people's satisfaction is the source of strength for the continuous advancement of transportation poverty alleviation. "People-centered" principle is the salient feature of socialism with Chinese characteristics. Transportation poverty alleviation work always insists on relying on the people, mobilizing the people's enthusiasm, initiative, and creativity to build the roads the people want mostly. People's Transportation always insists on sharing by the people, vigorously promotes the equalization of basic public services in urban and rural areas, makes the shared development results satisfactory to the people, strives to meet the people's yearning for a better life, strives to solve the problem of road construction and improvement and practically build the "Four Good Rural Roads" into the road to wealth, happiness, and connection for the common people.

The overall promotion of building, management, maintenance and transportation is to ensure the right 
course of the stable development of transportation poverty alleviation. Transportation poverty alleviation is a systematic project that "building well" is the foundation, "good management" is the focus, "good maintenance" is the guarantee, and "good operation" is the goal. Only by insisting on comprehensive and coordinated development can the system be optimized. While speeding up the shortcomings of transportation construction in poor areas, we will make every effort to promote the reform of rural road management and maintenance, continue to improve the level of passenger and cargo transportation services, and strive to integrate transportation poverty alleviation into the large ecology of industry, logistics, environment, and characteristic economy in rural areas, so as to promote the coordinated development of building, management, maintenance and transportation, and maximize the overall effectiveness.

\subsection{Method dimension:To promote the task of transportation poverty alleviation with scientific methods}

To achieve practical results in transportation poverty alleviation, it is important to take precise measures according to local conditions. Targeted poverty alleviation can only achieve targeted poverty eradication. We should continuously improve the targeted poverty alleviation policy work system, formulate differentiated support policies combining "inclusive benefits" and "special benefits" according to the different levels of poverty in poverty-stricken areas, build corresponding road models based on local conditions, enrich the "transport +" poverty alleviation model, give full play to the resource endowments and comparative advantages of different regions to shake off poverty. On the basis of allround achievements of access to tarmac or cement roads in conditional administrative villages, we should also guide poor areas to take measures according to local conditions and steadily promote more transportation construction projects to be oriented towards villages and households, promote more traffic construction projects to enter villages and households, so as to further enhance the poor people's feeling of gain and happiness.

Adhering to innovative mechanisms and ensuring resource input are a solid guarantee for achieving the goal of transportation poverty alleviation. Transportation poverty alleviation adheres to the priority arrangement of poverty alleviation projects, guarantee of funds, connection of work, and priority implementation of measures, especially strides to areas of extreme poverty like the "three regions and three prefectures". The Ministry of Transport has substantially increased the central investment subsidy standards, especially when the scale of vehicle purchase tax available during the "13th Five-Year Plan" period is lower than expected, the scale of transportation poverty alleviation funds has continued to increase significantly, which has greatly reduced the pressure on local governments in poor areas to allocate funds. This gave full play to the guiding role of fiscal and taxation policies and the leverage of government investment, effectively mobilizing more financial capital and social capital to participate.

Cohesion of the strong synergy of governments is a solid foundation for the orderly advancement of transportation poverty alleviation. Taking the vehicle purchase tax subsidy funds as leverage, in accordance with the working mechanism whereby the central government makes overall plans, provincial-level governments take overall responsibility, and city and county governments ensure implementation, the Ministry of Transport signed the joint construction of transportation poverty alleviation agreement with 24 provinces, established and improved reward and punishment mechanisms, promoted the integration of the "Two Access" task and the construction of "Four Good Rural Roads" of transportation poverty alleviation into the performance appraisal of local governments, gave better play to the enthusiasm of the central and local governments, fully mobilized the market, especially the poor people's stability and initiative and worked together to achieve the goal of transportation poverty alleviation.

\section{ConClusions}

Transportation poverty alleviation has achieved tangible results, bringing popularity and wealth to impoverished areas, and also consolidating popular support for the party at the grassroots level. Through the exploration, innovation and implementation of transportation poverty alleviation policy tools, the governance efficiency of the transportation industry has been greatly improved, and the outlook of transportation development has been fundamentally changed. The successful experience of transportation poverty alleviation is an organic part of the successful practice of targeted poverty alleviation, and at the same time, it has distinct industry characteristics. It is a valuable asset in the poverty alleviation experience system. It also has a strong guiding significance for further implementing rural revitalization strategy in transportation services and accelerating the construction of a country with strong transportation network.

Shaking off poverty is not the finish line, but the starting point of a new life and new endeavor. After completing the task of poverty alleviation as scheduled, the issues relating to agriculture, rural areas, and rural people have entered a new stage of comprehensively promoting rural revitalization. The Fifth Plenary Session of the 19th CPC Central Committee made a comprehensive deployment for demanding efforts to consolidate poverty alleviation achievements and initiate a dovetailing drive of "rural vitalization." Researchers gave suggestions in terms of the logical relationship, key 
content, and policy direction of the effective connection between the strategy of poverty alleviation and rural revitalization. On the basis of summarizing and analyzing the experience of the "Thirteenth Five-Year" transportation poverty alleviation, in accordance with the requirements of adapting to the new development stage, implementing the new development concept, and building a new development pattern, the transportation industry should further give full play to the role of pioneers and support and serve the overall rural revitalization which needs to combine the characteristics of the industry. It is necessary to have an effective transition in time to promote transportation poverty alleviation from consolidating poverty alleviation outcomes to achieve rural vitalization with the policies strictly implemented to be responsible, policy-oriented, supportive, and supervise in areas shaking off poverty during the five-year transition period. It is necessary to make overall plans for the work tasks transition, build a number of regional and cross-regional key infrastructure projects, promote the high-quality development of the "Four Good Rural Roads", put the development of the service industry in a more prominent position, and further complement the shortcomings of rural transportation. In the "14th Five-Year Plan" and investment policies, policy elements should be effectively guaranteed, namely the overall planning of the project, funds, talents, and technical supports to continuously strengthen the motivation of promoting comprehensive revitalization in areas that have shaken off poverty.

\section{REFERENCES}

[1] J. Zhao, X. B. Deng, L. Hou, (2018)Rural Revitalization Strategy and the Construction of "Four-Good Rural Roads", China Transportation Review,vol. 40, pp. 13-22.

[2] Y. H. Wang, Q. F. Shu,J. Clerk Maxwell, (2021)The Poverty Reduction Logic and Practical Approach of the Industrial Poverty Alleviation in China, Journal of Tsinghua University(Social Science Edition), vol. 1, pp.141-155+205.

[3] B.C. Chaffin, H. Gosnell\&B.A. Cosens, (2014)A Decade of Adaptive Governance Scholarship:Synthesis And Future Directions,Ecology And Society,Volume 19,Issue 3,p.56.

[4] M.E.B. Herrera, (2016)Innovation for Impact: Business Innovation for Inclusive Growth, Journal of Business Research, Volume 69, Issue 5,Pp.17251730.

[5] J. Donaldson, (2016)How China Escaped the Poverty Trap, Ithaca and London: Cornell University Press. 